\title{
Predictors and trends of contrast use and radiation exposure in a large cohort of patients treated with percutaneous coronary interventions: Chronic total occlusion analysis based on a national registry
}

\author{
Rafał Januszek $^{1,2}$, Leszek Bryniarski ${ }^{1,3}$, Zbigniew Siudak ${ }^{4}$, Krzysztof Piotr Malinowski ${ }^{3}$, \\ Sławomir Surowiec ${ }^{1}$, Krzysztof Bryniarski ${ }^{5}$, Magdalena Jędrychowska ${ }^{1}$, \\ Wojciech Wańha ${ }^{6}$, Krzysztof Bartuś ${ }^{7}$, Wojciech Wojakowski ${ }^{6}$, Jarosław Wójcik ${ }^{8}$, \\ Jacek Legutko ${ }^{5}$, Andrzej Surdacki ${ }^{1,3}$, Stanisław Bartuśs, \\ ${ }^{1}$ Department of Cardiology and Cardiovascular Interventions, University Hospital, Krakow, Poland \\ ${ }^{2}$ Department of Clinical Rehabilitation, University of Physical Education, Krakow, Poland \\ ${ }^{3}$ Department of Cardiology, Jagiellonian University Medical College, Krakow, Poland \\ ${ }^{4}$ Collegium Medicum, Jan Kochanowski University, Kielce, Poland \\ ${ }^{5}$ Department of Interventional Cardiology, Institute of Cardiology, Jagiellonian University \\ Medical College, John Paul II Hospital, Krakow, Poland
}

${ }^{6}$ Department of Cardiology and Structural Heart Diseases, Medical University of Silesia, Katowice, Poland

${ }^{7}$ Department of Cardiovascular Surgery and Transplantology, Jagiellonian University

Medical College, John Paul II Hospital, Krakow, Poland

${ }^{8}$ Department of Cardiology, Hospital of Invasive Cardiology IKARDIA, Naleczow, Poland

\begin{abstract}
Background: The aim herein, was to assess predictors and current trends of radiation exposure and total contrast amount use in patients treated with percutaneous coronary intervention within chronic total occlusion (CTO PCI) and non-CTO PCI.

Methods: Based on a nationwide registry (ORPKI), 535,857 patients treated with PCI between 2014 and 2018 were analyzed. The study included 12,572 (2.34\%) patients treated with CTO PCI. The CTO PCI and non-CTO PCI groups were compared before and after propensity score matching (PSM). Multifactorial mixed regression models were used to assess predictors of contrast amount use and radiation exposure. Results: The mean total contrast dose and radiation exposure decrease reached statistical significance in following years for the CTO PCI $(p=0.002$ and $p<0.001)$ and non-CTO PCI groups $(p<0.001$ and $p<0.001)$. Multifactorial analysis revealed that non-CTO PCI was a strong independent predictor of lower total contrast dose (estimate: -17.41 ; 95\% confidence interval [CI]: -18.45 to $-16.49, p<0.001$ ) and radiation exposure (estimate: -264.28 ; 95\% CI: -273.75 to -254.81, $p<0.001$ ). After PSM, it was confirmed that CTO PCI was an independent predictor of greater radiation exposure (estimate: 328.6; 95\% CI: 289.1-368.1; $p<0.001$ ) and total contrast dose (estimate: 30.5; 95\% CI: 27.28-33.74; $p<0.001$ ). Conclusions: Contrast dose and radiation exposure have decreased in previous years with regard to the CTO PCI and non-CTO PCI groups. CTO PCI was found to be an independent predictor of greater total contrast dose and radiation exposure in the overall group of patients treated with PCI. (Cardiol J)

Key words: contrast dose, chronic total occlusion, percutaneous coronary intervention, radiation exposure
\end{abstract}

Address for correspondence: Rafał Januszek, MD, PhD, Department of Cardiology and Cardiovascular Interventions, University Hospital, ul. Jakubowskiego 2, 30-688 Kraków, Poland, tel/fax: +48 12400 22 50/67, e-mail: jaanraf@interia.pl 


\section{Introduction}

The incidence of percutaneous coronary interventions within chronic total occlusion (CTO PCIs) in the overall group of examined patients treated with PCI is estimated to be between $5.5 \%$ and $12 \%$ according to the registry, the incidence of CTOs in the overall group of patients undergoing coronary angiography ranges between $15 \%$ and $20 \%$, however, in selected analyses, it reaches even more than half of the values presented for diagnostic heart catheterization [1-6]. The frequency of CTOs depends, among others, on the definition of CTO or mode of diagnostic coronary angiography. It is estimated that from the group of patients with CTO diagnosed during coronary angiography, roughly, 1/3 of them will undergo an attempt of CTO PCI (10\%) or surgical revascularization (20\%) [4]. According to the current European guidelines, percutaneous revascularization of CTOs should be considered in patients with angina resistant to medical therapy or with a large area of documented ischemia within the territory of the occluded artery (class IIa B) [7]. A large percentage of patients remain under pharmacological therapy due to limited evidence regarding the risk/benefit ratio and asymptomatic coronary atherosclerosis [8]. In recently published studies, it has been confirmed that there is superiority of PCI over medical therapy in patients with CTO $[9,10]$. Variability in the frequency of CTO PCIs was observed according to the volume of the center [4]. Percutaneous revascularization of CTOs is associated with an increased risk of specific procedure-related complications, including those vascular - with leading coronary artery perforation, and with longer procedure time of contrastinduced nephropathy (CIN), radiation exposure as well as loss of collateral circulation [3, 11].

Therefore, in the present study, the aim was to assess predictors and current trends of radiation exposure and total contrast amount use in an overall group of patients treated with PCI and with special insight into CTO PCIs.

\section{Methods}

\section{Study design and patient population}

This retrospective analysis was performed on prospectively collected data [12]. Data for conducting the current study were obtained from the National Registry of Percutaneous Coronary Interventions (ORPKI), maintained in cooperation with the Polish Cardiac Society's Association of Cardiovascular Interventions (AISN). The regis- try has been described in previously published papers $[12,13]$. Data were obtained from the registry between January 2014 and December 2018. 12,572 patients treated with $\mathrm{PCI}$ within CTO were selected out of 535,857 patients treated using PCI during the analyzed period. The technical aspects of the procedure, such as the choice of access site (femoral or radial), culprit lesion approach (antegrade or retrograde), sheath and catheter size, as well as guidewires, microcatheters and other devices specific for CTO PCIs, were at the operator's discretion. Furthermore, the periprocedural anticoagulation and indications for PCI as well as stent type remained at the first operator's discretion. Antiplatelet therapy was initiated according to current European guidelines [14]. The protocol complied with the 1964 Declaration of Helsinki, and all participants provided their written informed consent to participate in the percutaneous intervention. Due to the retrospective nature and anonymization of the collected data and registry, obtaining the consent of the Bioethics Committee was not required.

\section{Study endpoints}

Primary study endpoints included the total amount of contrast used during the procedure and entire radiation exposure in following years assessed in the presented study. Prior to propensity score matching (PSM), predictors of contrast amount and radiation dose in the overall group of patients treated with PCI were calculated. After PSM, the effect of PCI within CTO on the total amount of contrast used during the PCI and whole radiation exposure was also assessed.

\section{Statistical analysis}

Categorical variables are presented as numbers and percentages. Continuous variables are expressed as mean (standard deviation [SD]) or median (interquartile range [IQR]), where applicable. Normality was assessed via the Shapiro-Wilk test. Equality of variance was evaluated using Levene's test. Differences between the two groups were compared using the Student or Welch t-test, depending on the equality of variance for normally distributed variables. The Mann-Whitney U-test was applied for non-normally distributed continuous variables. Categorical variables were compared using the Pearson chi-squared or the Fisher exact test if $20 \%$ of the cells had an expected count of less than 5 (Monte Carlo simulation for the Fisher test was used with tables of greater dimensions than $2 \times 2$ ). All of the baseline/demographic 
Table 1. Clinical characteristics at baseline for patients treated with $\mathrm{PCl}$ according to culprit lesion type - CTO vs. non-CTO.

\begin{tabular}{lcccc}
\hline Variables & $\begin{array}{c}\text { Total } \\
\text { (n = 535,853) }\end{array}$ & $\begin{array}{c}\text { Non-CTO } \\
(\mathbf{n}=523,281)\end{array}$ & $\begin{array}{c}\text { CTO } \\
(\mathbf{n}=12,572)\end{array}$ & P \\
\hline Age [years] & $67.1 \pm 10.8$ & $67.1 \pm 10.8$ & $66.6 \pm 10.3$ & $<0.001$ \\
Weight [kg] & $80.9 \pm 16.9$ & $80.9 \pm 16.9$ & $83.2 \pm 16.1$ & $<0.001$ \\
Gender, male & $363,574(67.9)$ & $354,147(67.7)$ & $9,427(75)$ & $<0.001$ \\
Diabetes & $127,441(23.8)$ & $123,969(23.7)$ & $3,472(27.6)$ & $<0.001$ \\
Arterial hypertension & $378,874(70.7)$ & $369,259(70.6)$ & $9,615(76.5)$ & $<0.001$ \\
Prior stroke & $17,507(3.3)$ & $17,015(3.2)$ & $492(3.9)$ & $<.001$ \\
Prior myocardial infarction & $163,353(30.5)$ & $157,452(30.1)$ & $5,901(46.9)$ & $<0.001$ \\
Prior PCl & $198,339(37)$ & $192,360(36.8)$ & $5,979(47.6)$ & $<0.001$ \\
Prior CABG & $33,167(6.2)$ & $32,133(6.1)$ & $1,034(8.2)$ & $<0.001$ \\
Smoking & $106,123(19.8)$ & $103,412(19.8)$ & $2,711(21.6)$ & $<0.001$ \\
Kidney failure & $29,487(5.5)$ & $28,552(5.5)$ & $935(7.4)$ & $<0.001$ \\
COPD & $11,623(2.6)$ & $11,214(2.6)$ & $409(3.7)$ & $<0.001$ \\
Clinical presentation of CAD: & & & & $<0.001$ \\
$\quad$ Stable angina & $155,651(29.1)$ & $149,347(28.6)$ & $6,304(50.3)$ & $2,978(23.7)$ \\
$\quad$ Unstable angina & $155,141(29.0)$ & $152,163(29.1)$ & $1,615(12.9)$ & $1,420(11.3)$
\end{tabular}

Data are presented as mean \pm standard deviation or count (percentage); percentages reflect available study data; CTO — chronic total occlusion; CABG - coronary artery by-pass grafting; COPD — chronic obstructive pulmonary disease; CAD - coronary artery disease; NSTEMI - non-ST segment elevation myocardial infarction; $\mathrm{PCl}$ - percutaneous coronary intervention; STEMI — ST segment elevation myocardial infarction

characteristics included in the logistic regression model used PSM. PSM was performed with the nearest neighbour algorithm. The groups were considered balanced if standardised differences for each of the analyzed baseline/demographic characteristics were lower than $10 \%$. The PSM analysis included age, body mass, diabetes, prior stroke, prior myocardial infarction, prior PCI, prior coronary artery bypass grafting, smoking status, arterial hypertension, kidney disease, chronic obstructive pulmonary disease, vascular access, thrombectomy, rotablation use, thrombolysis in myocardial infarction (TIMI), flow grade prior to PCI, gender, clinical presentation at baseline, cardiac arrest before admission to the hospital, the use of imaging tests (fractional flow reserve [FFR], intravascular ultrasound [IVUS], optical coherence tomography [OCT]), the results of coronary artery angiography, type of PCI and culprit lesion. The effect of PCI within CTO on contrast use and radiation exposure was assessed using mixed-effect models to account for matching. Statistical analysis was performed using the R, version 3.5.3 (R Foundation for Statistical Computing, Vienna, Austria,
2019) with the following packages: 'MatchIt', version 3.0.2 and 'lme4', version 1.1-21.

\section{Results}

\section{Population}

Before PSM, a group of 523,128 patients treated with PCI and within the non-CTO culprit lesion were compared with 12,569 patients treated within the CTO culprit lesion.

\section{Patient characteristics}

Patients from the CTO group were characterized by significantly younger mean age $(66.6 \pm$ \pm 10.3 years vs. $67.1 \pm 10.8$ years, $\mathrm{p}<0.001)$ and a greater occurrence of males ( $75 \%$ vs. $67.7 \%$, $\mathrm{p}<0.001)$. This and other clinical indices are presented in Table 1.

\section{Coronary angiography and culprit lesion characteristics}

The frequency of patients with multi-vessel disease (MVD) and without left main coronary artery (LMCA) disease involvement, as well as 
Table 2. Coronary angiography and culprit lesion characteristics among patients treated with $\mathrm{PCl}$ according to coronary artery patency (CTO vs. non-CTO).

\begin{tabular}{|c|c|c|c|c|}
\hline Variables & $\begin{array}{c}\text { Total } \\
(\mathrm{n}=\mathbf{5 3 5 , 8 5 3 )}\end{array}$ & $\begin{array}{c}\text { Non-CTO } \\
(\mathrm{n}=523,281)\end{array}$ & $\begin{array}{c}\text { CTO } \\
(n=12,572)\end{array}$ & $\mathbf{P}$ \\
\hline Coronary angiography & & & & $<0.001$ \\
\hline SVD & $206,117(46.6)$ & $202,713(46.7)$ & $3,404(40.2)$ & \\
\hline MVD without LMCA & $211,418(47.8)$ & $206,868(47.7)$ & $4,550(53.7)$ & \\
\hline MVD and LMCA & $23,652(5.3)$ & $23,152(5.3)$ & $500(5.9)$ & \\
\hline Isolated LMCA & $1,156(0.3)$ & $1,142(0.3)$ & $14(0.2)$ & \\
\hline \multicolumn{5}{|l|}{ Location of culprit artery } \\
\hline Right coronary artery & $156,296(31.6)$ & $150,884(31.4)$ & $5,814(46)$ & $<0.001$ \\
\hline Left main coronary artery & $16,009(3.2)$ & $15,819(3.3)$ & $64(0.5)$ & $<0.001$ \\
\hline Left anterior descending artery & $186,974(37.8)$ & $183,150(38.1)$ & $3,811(30.2)$ & $<0.001$ \\
\hline Circumflex artery & $124,025(25.1)$ & $122,058(25.4)$ & $2,841(22.5)$ & $<0.001$ \\
\hline Intermediate artery & $8,519(1.7)$ & $8,376(1.7)$ & $100(0.8)$ & $<0.001$ \\
\hline Bifurcation & $9,410(8.3)$ & $9,248(8.3)$ & $162(6.0)$ & $<0.001$ \\
\hline Type of culprit lesion & & & & $<0.001$ \\
\hline De-novo & 440,847 (94.03) & $430,301(94.05)$ & $10,546(93.6)$ & \\
\hline Restenosis: & $25,256(5.39)$ & $24,559(5.37)$ & $697(6.19)$ & \\
\hline Drug-eluting stent & $17,344(3.70)$ & 16,895 (3.69) & 449 (3.99) & \\
\hline Bare-metal stent & $6,743(1.44)$ & $6,521(1.43)$ & $222(1.97)$ & \\
\hline Bioresorbable scaffold & $252(0.05)$ & $248(0.05)$ & $4(0.04)$ & \\
\hline Drug-coated balloon & $560(0.12)$ & $546(0.12)$ & $14(0.12)$ & \\
\hline Plain-old balloon angioplasty & $357(0.08)$ & $349(0.08)$ & $8(0.07)$ & \\
\hline In-stent thrombosis & $2,710(0.58)$ & $2,686(0.59)$ & $24(0.21)$ & \\
\hline
\end{tabular}

Data are presented as count (percentages); percentages reflect available study data; CTO — chronic total occlusion; LAD — left anterior descending coronary artery; LMCA — left main coronary artery; MVD — multi-vessel disease; PCI — percutaneous coronary intervention; SVD - single-vessel disease

patients with MVD and LMCA involvement was more frequent in the CTO group (53.7\% vs. $47.7 \%$; $5.9 \%$ vs. $5.3 \%$, respectively, $\mathrm{p}<0.001)$. These and other variables are presented in Table 2.

\section{Procedural indices}

Patients from the CTO group were more often treated from femoral approach in comparison to the non-CTO group (34.6\% vs. $24.9 \%$, p < 0.001$)$. Drug-eluting stents (DESs) were implanted significantly more often in the non-CTO group (44.9\% vs. $85.4 \%, \mathrm{p}<0.001)$. Those and other procedural indices are presented in Table 3.

\section{Contrast amount and radiation exposure}

Before PSM, mean radiation exposure (1658 \pm $\pm 1,269.7$ vs. $1,031.1 \pm 939.5 \mathrm{mGy}, \mathrm{p}<0.001)$ and the total contrast amount $(213.4 \pm 102.7$ vs. $171.9 \pm 75.6 \mathrm{~mL}, \mathrm{p}<0.001)$ was greater in the CTO group in comparison to non-CTO (Table 3). When considering trends in total contrast amount use at the assessed period of time (2014-2018), a significantly higher use of total contrast amount in the CTO compared to the non-CTO group in subsequent years of the analysed period ( $\mathrm{p}<$ $<0.001$ ) was observed, while a significant decrease was noted in recent years for the CTO $(\mathrm{p}=0.002)$ and non-CTO groups $(\mathrm{p}<0.001$, Fig. 1A). A similar trend was observed for radiation exposure, which has significantly decreased in recent years among the CTO $(\mathrm{p}<0.001)$ and non-CTO groups $(\mathrm{p}<0.001)$, and was significantly greater in subsequent years for the CTO group $(\mathrm{p}<0.001$, Fig. 1B).

\section{Catheterization laboratory and operator volume}

The total number of catheterization laboratories (CathLab) performing PCI within CTO was 164. The average number of CTO procedures per 1 CathLab was: $112 \pm 133$ (64 [28 $\div$ 139], range $0-602)$. The average percent of CTO procedures 
Table 3. Procedural indices among patients treated with $\mathrm{PCl}$ according to coronary artery patency of (CTO vs. non-CTO).

\begin{tabular}{|c|c|c|c|c|}
\hline Variables & $\begin{array}{c}\text { Total } \\
(\mathrm{n}=535,853)\end{array}$ & $\begin{array}{c}\text { Non-CTO } \\
(\mathrm{n}=523,281)\end{array}$ & $\begin{array}{c}\text { CTO } \\
(n=12,572)\end{array}$ & $\mathbf{P}$ \\
\hline Vascular access, femoral & $133,364(25.1)$ & $129,055(24.9)$ & $8,153(34.6)$ & $<0.001$ \\
\hline Fractional flow reserve & $10,355(1.9)$ & $10,224(1.9)$ & $131(1.0)$ & $<0.001$ \\
\hline Intravascular ultrasound & $6,442(1.2)$ & $6,263(1.2)$ & $179(1.4)$ & 0.02 \\
\hline Optical coherence tomography & $992(0.2)$ & $912(0.2)$ & $80(0.6)$ & $<0.001$ \\
\hline Rotablation & $2,710(0.5)$ & $2,604(0.5)$ & $106(0.8)$ & $<0.001$ \\
\hline TIMI flow grade before $\mathrm{PCl}$ : & & & & $<0.001$ \\
\hline 0 & $107,446(20.8)$ & $97,656(19.4)$ & $9,970(78.7)$ & \\
\hline Other than 0 & $408,776(79.2)$ & $406,128(80.6)$ & $2,648(21.3)$ & \\
\hline TIMI flow grade after $\mathrm{PCl}$ : & & & & $<0.001$ \\
\hline 0 & $11,712(2.3)$ & $7,799(1.5)$ & $3,913(31.5)$ & \\
\hline 1 & $5,419(1)$ & $4,737(0.9)$ & $682(5.5)$ & \\
\hline 2 & $14,896(2.9)$ & $14,372(2.9)$ & $524(4.2)$ & \\
\hline 3 & $484,862(93.8)$ & $477,547(94.7)$ & $7,315(58.8)$ & \\
\hline Culprit artery patency after $\mathrm{PCl}$ : & & & & $<0.001$ \\
\hline Absent (TIMI grade 0 and 1 ) & $17,131(3.3)$ & $12,536(2.5)$ & $4,595(36.7)$ & \\
\hline Present (TIMI grade 2 and 3 ) & $499,758(96.7)$ & $491,919(97.5)$ & $7,839(63)$ & \\
\hline Type of PCl: & & & & $<0.001$ \\
\hline Drug-eluting stent & $452,793(84.5)$ & $447,148(85.4)$ & $5,645(44.9)$ & \\
\hline Bare-metal stent & $21,265(4.0)$ & $21,243(4.1)$ & $22(0.2)$ & \\
\hline Bioresorbable stent & $4,574(0.8)$ & $4,280(0.8)$ & $294(2.3)$ & \\
\hline DCB/POBA/Failed angioplasty & $57,220(10.7)$ & $50,609(9.7)$ & $6,611(52.6)$ & \\
\hline Procedural related complications & $10,462(1.95)$ & $10,115(1.93)$ & $346(2.75)$ & $<0.001$ \\
\hline Radiation dose [mGy] & $\begin{array}{c}1045.4 \pm 952.9 \\
789[446 \div 1340]\end{array}$ & $\begin{array}{c}1,031.1 \pm 939.5 \\
780[441 \div 1321]\end{array}$ & $\begin{array}{c}1658 \pm 1269.7 \\
1334[765 \div 2188]\end{array}$ & $<0.001$ \\
\hline Contrast amount [mL] & $\begin{array}{c}172.8 \pm 76.8 \\
150[120 \div 200]\end{array}$ & $\begin{array}{c}171.9 \pm 75.6 \\
150[120 \div 200]\end{array}$ & $\begin{array}{c}213.4 \pm 102.7 \\
200[150 \div 250]\end{array}$ & $<0.001$ \\
\hline
\end{tabular}

Data are presented as mean \pm standard deviation, median [interquartile range] or count (percentage); percentage reflects available study data; CTO - chronic total occlusion; DCB - drug-coated balloon; $\mathrm{PCl}$ - percutaneous coronary intervention; POBA - plain-old balloon angioplasty; TIMI - thrombolysis in myocardial infarction

per 1 CathLab was: $2.35 \pm 2.16(1.85[0.67 \div$ 3.1 , range $0-11.71)$. Total radiation exposure per 1 procedure was not correlated with number of procedures per 1 CathLab $(\mathrm{R}=0.017)$ or with the percent of procedures $(\mathrm{R}=0.025)$.

Total contrast dose per 1 procedure was neither correlated with number of procedures per 1 CathLab $(\mathrm{R}=0.042)$ nor with the percent of procedures $(R=0.034)$. The number of operators was not available in the presented analysis (Fig. 2).

\section{Propensity score matching}

A comparison of selected indices between the CTO and non-CTO groups after PSM is presented in Table 4.

\section{Predictors of increased radiation dose and contrast amount}

Predictors of contrast amount used during PCI are presented on the Figure 3, while predictors of radiation exposure are presented on Figure 4. Following PSM, PCI within the CTO lesion remained significantly correlated with the increased total use of contrast amount (estimate: 30.5, 95\% CI: 27.28-33.74; $\mathrm{p}<0.001$ ) and greater radiation exposure (estimate: 328.6, 95\% CI: 289.1-368.1; p < 0.001).

\section{Discussion}

The main finding of the current study was that over subsequent years, the total contrast amount 


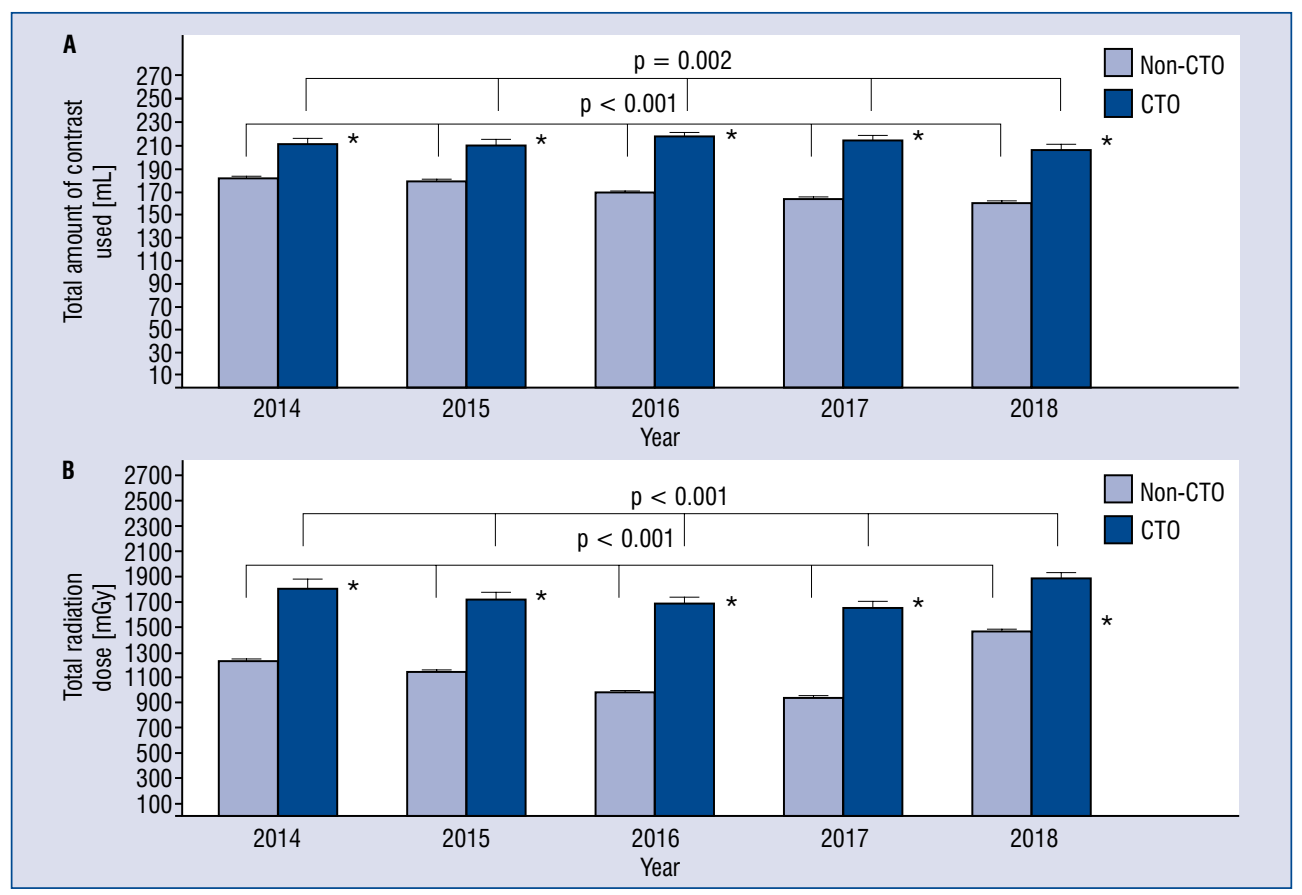

Figure 1. A. Mean contrast amount used per 1 percutaneous coronary intervention (PCl) procedure in following years (2014-2018), among patients treated within chronic total occlusion (CTO) and non-CTO culprit lesions. Each error bar is constructed using a 95\% confidence interval of the mean; ${ }^{*}$ if $p<0.001$ comparing patients in the CTO and non-CTO group during individual years; B. Mean radiation dose used per 1 PCl procedure in following years (2014-2018), among patients treated within CTO and non-CTO culprit lesions. Each error bar is constructed using a 95\% confidence interval of the mean; *if $\mathrm{p}<0.001$ comparing patients in the CTO and non-CTO group during individual years.

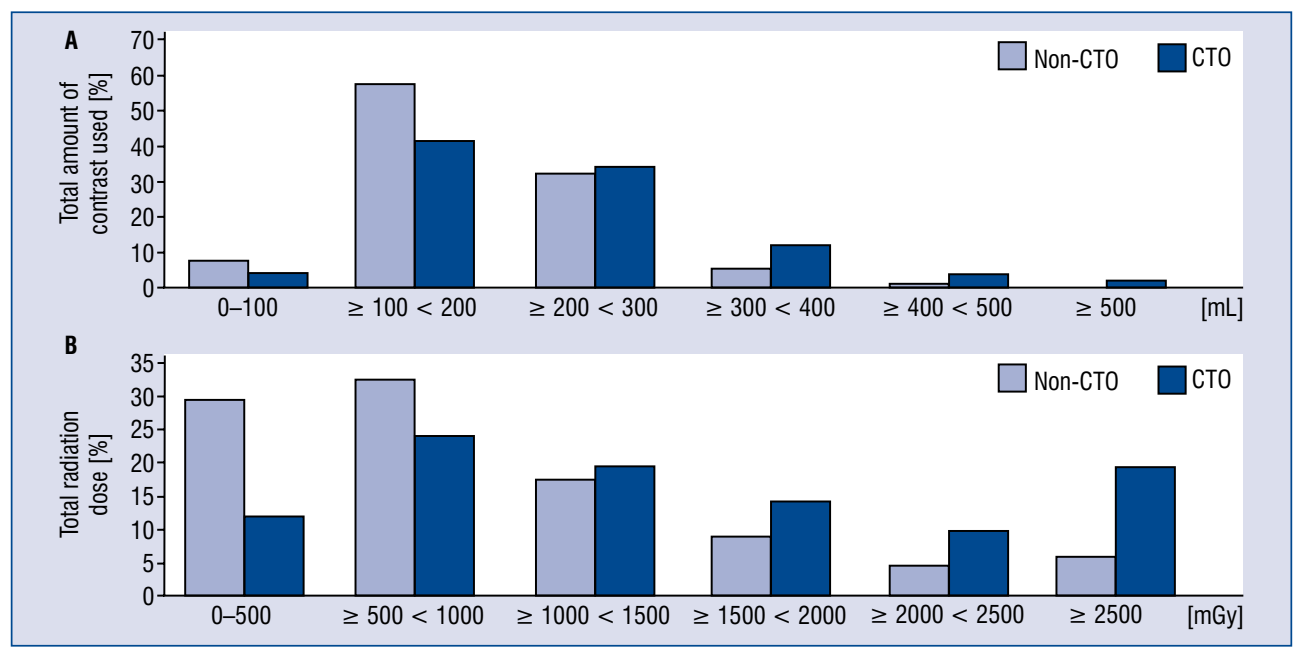

Figure 2. A. Frequency distribution of total contrast volume used during the chronic total occlusion (CTO) and nonCTO procedures; B. Frequency distribution of total radiation exposure in CTO and non-CTO procedures.

and radiation exposure remained significantly higher in CTO PCI group in comparison to the non-CTO PCI group. Moreover, the total contrast dose and radiation exposure decreased significantly in following years in the CTO PCI as well as non-
-CTO PCI groups. Among several predictors, CTO PCI was an independent one of greater total contrast amount and radiation exposure in the overall group of patients treated with PCI. Importantly, after PSM, between the CTO PCI and non-CTO PCI groups, 
Table 4. Comparison between the group of patients treated with $\mathrm{PCl}$ after propensity score matching according to culprit lesion type - CTO and non-CTO.

\begin{tabular}{|c|c|c|}
\hline & $\begin{array}{l}\text { Non-CTO } \\
(n=5,652)\end{array}$ & $\begin{array}{c}\text { CTO } \\
(n=5,652)\end{array}$ \\
\hline Age & $67.2 \pm 10.8$ & $67.0 \pm 10.4$ \\
\hline Weight [kg] & $83.1 \pm 16.3$ & $83.4 \pm 16.5$ \\
\hline Gender, males & $4,044(71.5)$ & $4,173(73.8)$ \\
\hline Diabetes & $1,570(27.8)$ & $1,592(28.2)$ \\
\hline Prior stroke & $253(4.5)$ & $237(4.2)$ \\
\hline Prior myocardial infarction & $2,223(39.3)$ & $2,337(41.3)$ \\
\hline Prior $\mathrm{PCl}$ & $2,115(37.4)$ & $2,241(39.6)$ \\
\hline Prior CABG & $464(8.2)$ & $440(7.8)$ \\
\hline Smoking & $1,298(23.0)$ & $1,308(23.1)$ \\
\hline Arterial hypertension & $4,214(74.6)$ & $4,285(75.8)$ \\
\hline Kidney disease & $397(7.0)$ & $407(7.2)$ \\
\hline Chronic obstructive pulmonary disease & $251(4.4)$ & $259(4.6)$ \\
\hline Vascular access, femoral & $1,498(26.5)$ & $1,431(25.3)$ \\
\hline Rotablation & $29(0.5)$ & $28(0.5)$ \\
\hline TIMI flow grade before $\mathrm{PCl}$ other than 0 & $1,207(21.4)$ & $1,328(23.5)$ \\
\hline Contrast amount [mL] & $175.5 \pm 79.42$ & $205.7 \pm 95.2$ \\
\hline Radiation dose [mGy] & $1,191.4 \pm 1,000.6$ & $1,521.8 \pm 1,137.2$ \\
\hline Procedure-related complications & $256(4.5)$ & $175(3.1)$ \\
\hline Dissection & $23(0.4)$ & $3(0.1)$ \\
\hline \multicolumn{3}{|l|}{ Indication: } \\
\hline Stable angina & $1,743(30.8)$ & $2,137(37.8)$ \\
\hline Unstable angina & $1,823(32.3)$ & $1,694(30.0)$ \\
\hline NSTEMI & $1,086(19.2)$ & $985(17.4)$ \\
\hline STEMI & $806(14.3)$ & $676(12.0)$ \\
\hline Others & $194(3.4)$ & $160(2.8)$ \\
\hline Cardiac arrest before admission & $140(2.5)$ & $104(1.8)$ \\
\hline IVUS+FFR+OCT & $157(2.8)$ & $179(3.2)$ \\
\hline \multicolumn{3}{|l|}{ Coronary angiography: } \\
\hline Single vessel disease & $2,116(37.4)$ & $2,211(39.1)$ \\
\hline MVD - LMCA & $3,027(53.6)$ & $3,006(53.2)$ \\
\hline MVD + LMCA & $502(8.9)$ & $427(7.6)$ \\
\hline Separate LMCA & $7(0.1)$ & $8(0.1)$ \\
\hline \multicolumn{3}{|l|}{ Type of PCl: } \\
\hline DES & $2,329(41.2)$ & $2,381(42.1)$ \\
\hline BMS & $13(0.2)$ & $11(0.2)$ \\
\hline BRS & $115(2.0)$ & $125(2.2)$ \\
\hline DCB/POBA/Failed angioplasty & $3,195(56.5)$ & $3,135(55.5)$ \\
\hline \multicolumn{3}{|l|}{ Type of culprit lesion: } \\
\hline De-novo & $5,196(91.9)$ & $5,233(92.6)$ \\
\hline Restenosis & $441(7.8)$ & $403(7.1)$ \\
\hline Thrombosis & $15(0.3)$ & $16(0.3)$ \\
\hline
\end{tabular}

Data are presented as mean \pm standard deviation or count (percentage); percentages reflect available study data; CTO — chronic total occlusion; BMS - bare-metal stent; BRS — bioresorbable scaffold; CABG — coronary artery bypass grafting; DES — drug-eluting stent; FFR - fractional flow reserve; IVUS — intra-vascular ultrasound; LMCA - left main coronary artery; MVD - multi-vessel disease; NSTEMI non-ST segment elevation myocardial infarction; OCT — optical coherence tomography; PCI — percutaneous coronary intervention; STEMI ST-segment elevation myocardial infarction; TIMI - thrombolysis in myocardial infarction 


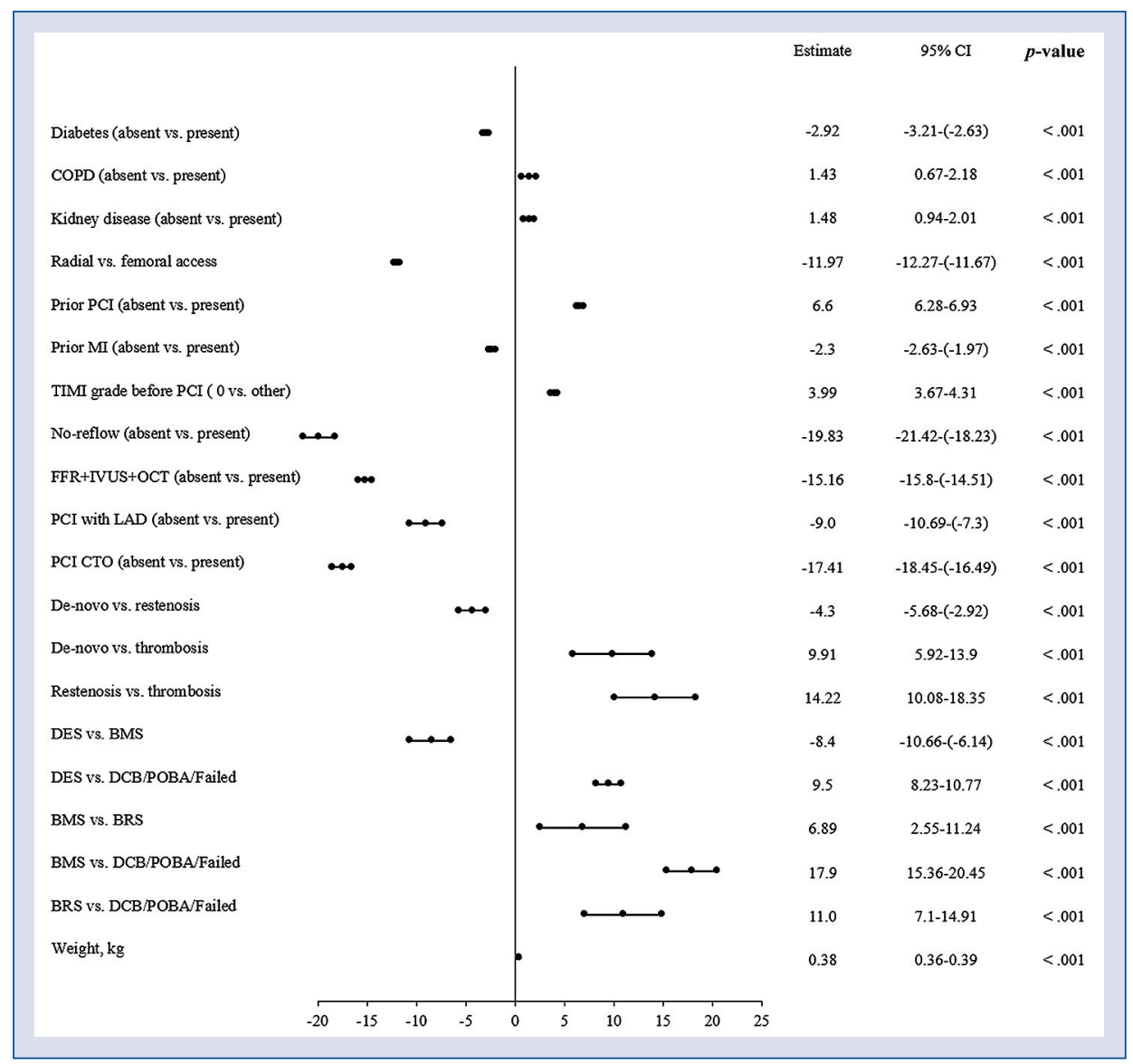

Figure 3. Predictors of increased contrast use in the overall group of patients treated with percutaneous coronary intervention (PCI) - before propensity score matching (PSM); BMS - bare-metal stent; BRS - bioresorbable scaffold; $\mathrm{Cl}$ - confidence interval; COPD - chronic obstructive pulmonary disease; CTO — chronic total occlusion; DCB — drug-coated balloon; DES — drug-eluting stent; FFR — fractional flow reserve; IVUS — intravascular ultrasound; LAD - left anterior descending coronary artery; $\mathrm{MI}$ - myocardial infarction; OCT — optical coherence tomography; POBA — plain-old balloon angioplasty; TIMI - thrombolysis in myocardial infarction.

the former was still a significant predictor of greater total contrast amount use and radiation exposure.

\section{Contrast amount}

In the presented analysis, it was found that concomitant kidney disease is related to the lower use of contrast during PCI in the overall group of patients, which seems to be justified by greater probability of kidney failure and greater consideration of the operators paid to the amount of contrast used during PCI. A similar relationship was observed for chronic obstructive pulmonary disease and prior PCI. The presence of diabetes was found to be related to the greater amount of contrast use during the PCI procedure, which may be explained by more disseminated atherosclerosis and potentially more complicated procedures. Moreover, lack of patency before PCI expressed as TIMI grade flow 0 , the presence of no-reflows and the use of more complicated imaging devices (FFR/IVUS/OCT) were indicative of greater contrast use amounts. No-reflows demand longer procedures and multiple cine angiographies after infusion of particular agents in the treatment of coronary flow disturbances. PCI within occluded arteries at baseline is usually related to more complicated and longer procedures. Furthermore, PCI within restenosis is found to be a predictor of increased risk regarding higher contrast use in comparison to de-novo lesions, which seems to be reasonable in terms of the degree of procedure difficulty. A similar relationship and explanation could be dedicated to thrombosis in comparison to de-novo culprit lesions. Femoral access usually concerns the use of greater guiding catheter diameters, potentially more complicated procedures or patients in more severe states. The 


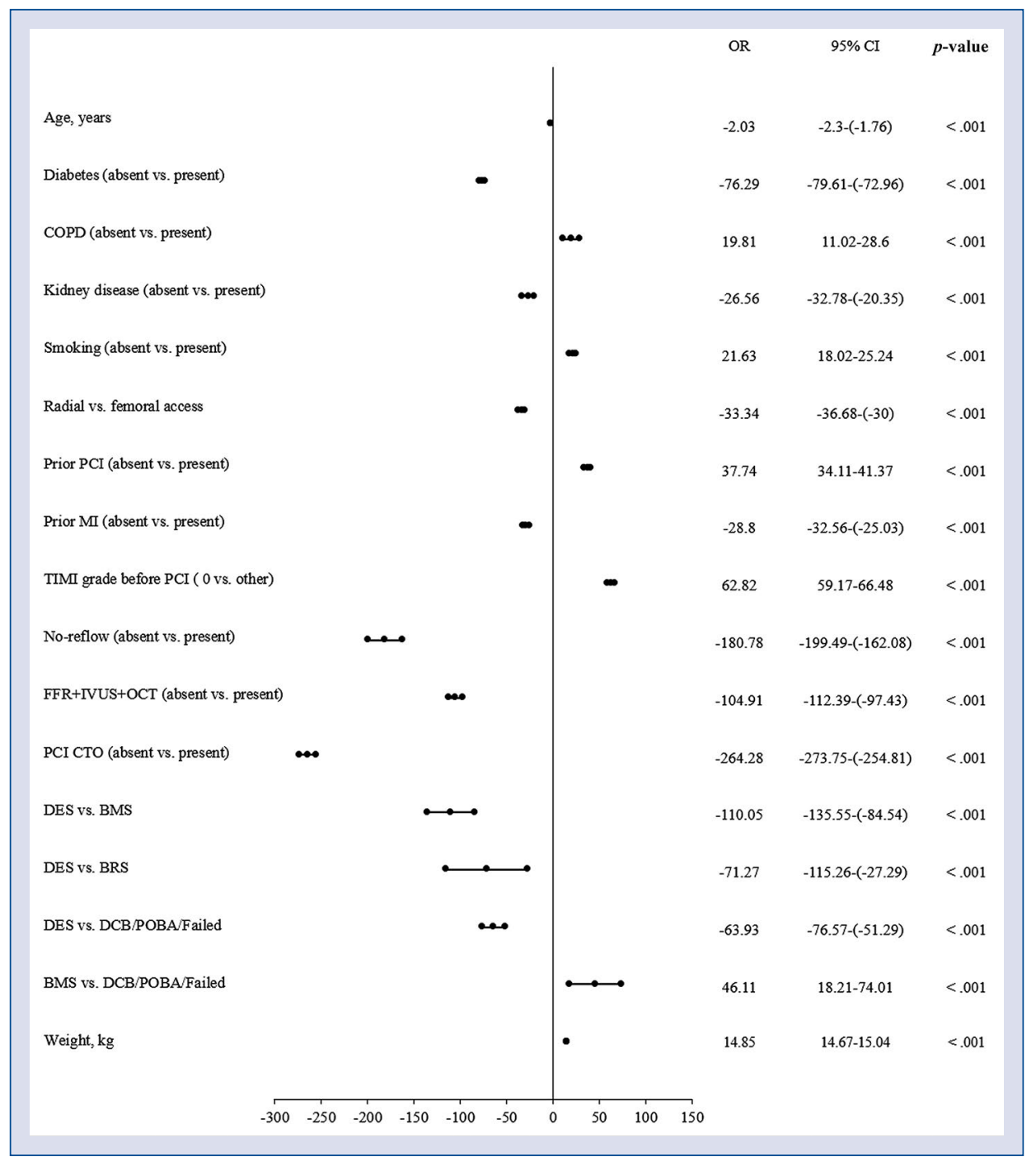

Figure 4. Predictors of increased radiation exposure in the overall group of patients treated with percutaneous coronary intervention (PCI) - before propensity score matching (PSM); BMS — bare-metal stent; BRS — bioresorbable scaffold; COPD - chronic obstructive pulmonary disease; CTO - chronic total occlusion; DCB — drug-coated balloon; DES — drug-eluting stent; FFR — fractional flow reserve; IVUS — intravascular ultrasound; LAD — left anterior descending coronary artery; $\mathrm{MI}$ - myocardial infarction; OCT — optical coherence tomography; POBA — plain-old balloon angioplasty; TIMI — thrombolysis in myocardial infarction.

relationship between body mass, as well as the dose of contrast and radiation, is well-sanctioned and requires no additional comments.

In the study published by Michael et al. [15], which included 1,363 consecutive CTO PCIs, performed at 3 institutions between January 2006 and November 2011, CTOs within the coronary arteries were defined as angiographic evidence of total occlusion with TIMI grade 0 or 1 and an estimated duration of at least 3 months [15]. The authors of that analysis confirmed that prior coronary artery bypass grafting, right coronary artery target vessel, fewer years since initiation of CTO PCI registry at each center, use of the retrograde approach and procedural failure, were independently associated with prolonged fluoroscopy duration [15]. In the study published by Michael et al. [15], the mean contrast amount used during 1 CTO PCI totaled $294 \pm 158 \mathrm{~mL}$ and $265 \mathrm{~mL}$. This was a significantly greater amount when compared to the present results and may be related to earlier years of the conducted analysis. At that time, similar results could be noticed in our population. Morino et al. [16], in their study based on the Multicenter CTO Registry in Japan, reported the median contrast volume per 1 CTO PCI to be $293 \mathrm{~mL}$ while CIN fre- 
quency was at $1.2 \%$. In a more recently published study, based on the PROGRESS-CTO registry, the results were comparable to those obtained in the present analysis [17]. While Konstantinidis et al. [18] reported the mean contrast volume in patients treated with CTO PCI, based on the 17,626 procedures from the European Registry of CTO at following periods of time, to be: $298 \mathrm{~mL}$ (2008-2009), $298 \mathrm{~mL}$ (2008-2009), $310 \mathrm{~mL}$ (2012-2013) and $280 \mathrm{~mL}$ (2014-2015). In another publication from the Japanese CTO-PCI Expert Registry, similar data to that obtained in the currently presented analysis was also reported [19].

\section{Radiation exposure}

Assessing predictors of radiation exposure in the overall group of patients treated with $\mathrm{PCI}$ in the present study, it was demonstrated that diabetes, kidney disease and femoral access are predictors of increased radiation exposure. Diabetes and kidney failure are usually related to more complicated, calcified and long-narrow arteries, which undoubtedly increase the difficulty of the procedure and are related with the use of additional devices such as rotablation. Also, the no-reflow phenomena and TIMI flow grade 0 were among predictors of greater radiation exposure, which could be related to a longer procedure duration. Considering the type of PCI, PCIs with bare-metal stent and bioresorbable scaffold implantation were predictors of greater radiation exposure when compared to DES implantation. The presence of CTO PCI was the strongest predictor among all the estimated indices of greater radiation exposure during the PCI procedure. This was also confirmed following PSM.

The median patient air kerma dose reported in a recently published study, which was based on the PROGRESS-CTO registry, was greater when compared to the current study and was $2.642 \mathrm{~Gy}$ for the years 2012-2019, 2.825 Gy for 2012-2016 and $2.382 \mathrm{~Gy}$ for 2017-2019 [17]. In a recent report from the European Registry of CTO, rather stable mean fluoroscopy durations are shown at the following assessed periods: $37 \mathrm{~min}$ (2008-2009), $49 \mathrm{~min}$ (2010-2011), $43 \mathrm{~min}$ (2012-2013) and $43 \mathrm{~min}$ (2014-2015) [18]. However, this can lead to erroneous conclusions, because nowadays, devices with lower radiation and lower frame rates are used, which in summary, allows implementation of radiation doses more slowly.

\section{Preventive actions}

Contrast-induced nephropathy, a common complication following PCI, is the $3^{\text {rd }}$ most common cause of acute renal failure in patients admitted to hospital, and it is associated with increased morbidity, mortality and medical costs [20]. Administration of higher contrast volumes is associated with higher risks of contrast nephropathy, and CTO PCI has been connected with high contrast volume administration [16, 21]. In a meta-analysis published by Patel et al. [22], the incidence of CIN was reported to be between $2.4 \%$ and $18.1 \%$, with a pooled estimate rate of $3.4 \%$. Therefore, all treatments applied in order to reduce the supply of contrast dose are highly desirable. Among several possible interventions aimed at contrast reduction, radial and biradial access were found to be superior over femoral access [23]. Special devices for contrast dosing during PCI have also been developed, the use of which has been proven to reduce the volume of contrast administered in patients undergoing PCI within CTO [24]. Recently, descriptions have also been published of successful attempts to perform PCI procedures within CTO, using gadolinium in combination with IVUS among patients with anaphylaxis to iodinated contrast agents [25].

In the case of increased radiation during PCI, we are mainly concerned with short-term effects such as radiation-induced dermatitis, as well as distant consequences, e.g. related to bone marrow damage or oncological diseases. Radiation dermatitis is the most common direct complication of high radiation exposure in CTO PCIs, and being a rare complication, in some publications, no such events have even been reported [16]. Recently, many factors have contributed to a decrease in radiation exposure during PCI and especially, CTO PCI. One of the $1^{\text {st }}$ statement documents which was published in 2011, recommended the use of 7.5 frames per 1 second of fluoroscopy [26]. Furthermore, other additional modifications are available and include increased copper filtering with lower entry dose in combination with modified post-processing image [27]. Nowadays, including the current center, 4 frames per second of fluoroscopy is mostly used. Among other recommendations advised in the document were: limiting the use of cine angiography and applying the "fluoro-store" function instead; optimizing the position of the table and image intensifier; rotating the image intensifier to distribute radiation exposure to multiple skin entry sites; using shielding; closely monitoring radiation exposure throughout the duration of the procedure; and terminating the procedure if a pre-defined threshold is reached without successful lesion crossing [26]. In older studies, it 
has been reported that CTO PCIs, compared to non-CTO, are related to as much as $40 \%$ higher radiation exposure [28]. Currently, it is clearly visible in the presented analysis that this difference remains similar, besides the fact that the overall radiation exposure permanently and statistically significantly decreased in following years among the CTO PCI and non-CTO PCI groups. It has been demonstrated that modern $\mathrm{X}$-ray equipment enables introduction of modified protocols aimed at a drastic reduction of the fluoroscopy exposure [29]. Another factor proven to be related with lower radiation exposure was biradial vascular access [23].

\section{Strengths and limitations of the study}

The greatest strength of the presented study is the large number of examined patients, as analyses carried out among such numerous patient groups $\mathrm{s}$ with CTO are rare. However, from a number of limitations of the current study, those that should be addressed in the first place include the nature of the analysis. The research was retrospective, carried out on the basis of a prospectively collected registry. Many of the disadvantages of such a registry include, but are not limited to, estimating the frequency of periprocedural complications arising from the registry itself, which further include complications only during the time of procedure and the early post-procedural period when the patient is still at the catheterization laboratory. This enables assessment of the number of patients with CIN or radiation dermatitis. Another important issue is that recognising the culprit lesion as CTO was at the discretion of the operator and depended on his/her knowledge, habits or inclinations, which, unfortunately, imposes bias. Other well-recognized predictors of contrast dose or radiation exposure in the current analysis was not possible to include because the analyzed database did not contain such data. These would include such parameters as culprit lesion characteristics (length, diameter, location, tortuosity, extent of calcification, etc.), type of devises used for PCI (guidewires, microcatheters as well as type of vascular approach: retrograde vs. antegrade), number of prior attempts to perform CTO PCI. These missing values could have significantly modified the results and caused some bias. In the presented analysis, the relationship between operator volume and contrast amount or radiation exposure was also not taken into consideration due to a lack of data. It may be expected that more experienced operators use less contrast and radiation exposure.

\section{Conclusions}

Total contrast amount and radiation exposure remain significantly higher in CTO PCI compared to non-CTO PCI in subsequent years assessed in the current analysis. The total contrast dose and radiation exposure decreased statistically significantly in following years for the CTO PCI as well as the non-CTO PCI groups. Among several predictors, CTO PCI was found to be an independent one of greater total contrast amount dose and radiation exposure in the overall group of patients treated with PCI. After propensity score matching analysis between the CTO PCI and non-CTO PCI groups, CTO PCI was also confirmed as a significant predictor of greater total contrast amount and radiation exposure. Although the difference between the volume of contrast and radiation dose remains significant for CTO and non-CTO PCI, in both groups, the contrast dose and radiation exposure have decreased in recent years, which means that these actions aimed at their reduction are effective, but still require attention and improvement in many patients to decrease the incidence of preventable complications related to CTO PCI.

\section{Conflict of interest: None declared}

\section{References}

1. Råmunddal T, Hoebers LP, Hoebers L, et al. Chronic total occlusions in Sweden: a report from the Swedish Coronary Angiography and Angioplasty Registry (SCAAR). PLoS One. 2014; 9(8): e103850, doi: 10.1371/journal.pone.0103850, indexed in Pubmed: 25117457.

2. Anderson H, Shaw R, Brindis R, et al. A contemporary overview of percutaneous coronary interventions. J Am Coll Cardiol. 2002; 39(7): 1096-1103, doi: 10.1016/s0735-1097(02)01733-3.

3. Grantham JA, Marso SP, Spertus J, et al. Chronic total occlusion angioplasty in the United States. JACC Cardiovasc Interv. 2009; 2(6): 479-486, doi: 10.1016/j.jcin.2009.02.008, indexed in Pubmed: 19539249.

4. Fefer P, Knudtson ML, Cheema AN, et al. Current perspectives on coronary chronic total occlusions: the Canadian Multicenter Chronic Total Occlusions Registry. J Am Coll Cardiol. 2012; 59(11): 991-997, doi: 10.1016/j.jacc.2011.12.007, indexed in Pubmed: 22402070 .

5. Christofferson RD, Lehmann KG, Martin GV, et al. Effect of chronic total coronary occlusion on treatment strategy. Am J Cardiol. 2005; 95(9): 1088-1091, doi: 10.1016/j.amjcard.2004.12.065, indexed in Pubmed: 15842978.

6. Jeroudi OM, Alomar ME, Michael TT, et al. Prevalence and management of coronary chronic total occlusions in a tertiary Veterans Affairs hospital. Catheter Cardiovasc Interv. 2014; 84(4): 637-643, doi: 10.1002/ccd.25264, indexed in Pubmed: 24142769.

7. Neumann FJ, Sousa-Uva M, Ahlsson A, et al. ESC Scientific Document Group. 2018 ESC/EACTS Guidelines on myocardial 


\section{Cardiology Journal}

revascularization. Eur Heart J. 2019; 40(2): 87-165, doi: 10.1093/ eurhearti/ehy394, indexed in Pubmed: 30165437.

8. Brilakis ES, Banerjee S, Karmpaliotis D, et al. Procedural outcomes of chronic total occlusion percutaneous coronary intervention: a report from the NCDR (National Cardiovascular Data Registry). JACC Cardiovasc Interv. 2015; 8(2): 245-253, doi: 10.1016/j.jcin.2014.08.014, indexed in Pubmed: 25700746.

9. Werner GS, Martin-Yuste V, Hildick-Smith D, et al. EUROCTO trial investigators. A randomized multicentre trial to compare revascularization with optimal medical therapy for the treatment of chronic total coronary occlusions. Eur Heart J. 2018; 39(26): 2484-2493, doi: 10.1093/eurheartj/ehy220, indexed in Pubmed: 29722796.

10. Obedinskiy AA, Kretov EI, Boukhris M, et al. The IMPACTOR-CTO Trial. JACC Cardiovasc Interv. 2018; 11(13): 1309-1311, doi: 10.1016/j.jcin.2018.04.017, indexed in Pubmed: 29976368.

11. Galassi AR, Tomasello SD, Reifart N, et al. In-hospital outcomes of percutaneous coronary intervention in patients with chronic total occlusion: insights from the ERCTO (European Registry of Chronic Total Occlusion) registry. EuroIntervention. 2011; 7(4): 472-479, doi: 10.4244/EIJV7I4A77, indexed in Pubmed: 21764666.

12. Januszek R, Siudak Z, Dziewierz A, et al. Predictors of in-hospital effectiveness and complications of rotational atherectomy (from the ORPKI Polish National Registry 2014-2016). Catheter Cardiovasc Interv. 2018; 92(4): E278-E287, doi: 10.1002/ccd.27372, indexed in Pubmed: 29068164.

13. Januszek R, Dziewierz A, Siudak Z, et al. Chronic obstructive pulmonary disease and periprocedural complications in patients undergoing percutaneous coronary interventions. PLoS One. 2018; 13(10): e0204257, doi: 10.1371/journal.pone.0204257, indexed in Pubmed: 30273363.

14. Valgimigli M, Bueno H, Byrne RA, et al. ESC Scientific Document Group, ESC Committee for Practice Guidelines (CPG), ESC National Cardiac Societies. 2017 ESC focused update on dual antiplatelet therapy in coronary artery disease developed in collaboration with EACTS: The Task Force for dual antiplatelet therapy in coronary artery disease of the European Society of Cardiology (ESC) and of the European Association for CardioThoracic Surgery (EACTS). Eur Heart J. 2018; 39(3): 213-260, doi: 10.1093/eurheartj/ehx419, indexed in Pubmed: 28886622.

15. Michael TT, Karmpaliotis D, Brilakis ES, et al. Temporal trends of fluoroscopy time and contrast utilization in coronary chronic total occlusion revascularization: insights from a multicenter United States registry. Catheter Cardiovasc Interv. 2015; 85(3): 393-399, doi: 10.1002/ccd.25359, indexed in Pubmed: 24407867.

16. Morino Y, Kimura T, Hayashi Y, et al. J-CTO Registry Investigators. In-hospital outcomes of contemporary percutaneous coronary intervention in patients with chronic total occlusion insights from the J-CTO Registry (Multicenter CTO Registry in Japan). JACC Cardiovasc Interv. 2010; 3(2): 143-151, doi: 10.1016/j. jcin.2009.10.029, indexed in Pubmed: 20170870.

17. Xenogiannis I, Gkargkoulas F, Karmpaliotis D, et al. Temporal trends in chronic total occlusion percutaneous coronary interventions: insights from the PROGRESS-CTO registry. J Invasive Cardiol. 2020; 32(4): 153-160, indexed in Pubmed: 32198318.
18. Konstantinidis NV, Werner GS, Deftereos S, et al. Euro CTO Club. Temporal trends in chronic total occlusion interventions in Europe. Circ Cardiovasc Interv. 2018; 11(10): e006229, doi: 10.1161/CIRCINTERVENTIONS.117.006229, indexed in Pubmed: 30354635.

19. Suzuki Y, Tsuchikane E, Katoh O, et al. Outcomes of percutaneous coronary interventions for chronic total occlusion performed by highly experienced japanese specialists: the first report from the japanese CTO-PCI expert registry. JACC Cardiovasc Interv. 2017; 10(21): 2144-2154, doi: 10.1016/j.jcin.2017.06.024, indexed in Pubmed: 29055764.

20. Nash K, Hafeez A, Hou S. Hospital-acquired renal insufficiency. Am J Kidney Dis. 2002; 39(5): 930-936, doi: 10.1053/ ajkd.2002.32766, indexed in Pubmed: 11979336.

21. Tsai TT, Patel UD, Chang TI, et al. Contemporary incidence, predictors, and outcomes of acute kidney injury in patients undergoing percutaneous coronary interventions: insights from the NCDR Cath-PCI registry. JACC Cardiovasc Interv. 2014; 7(1): 1-9, doi: 10.1016/j.jcin.2013.06.016, indexed in Pubmed: 24456715.

22. Patel VG, Brayton KM, Tamayo A, et al. Angiographic success and procedural complications in patients undergoing percutaneous coronary chronic total occlusion interventions: a weighted meta-analysis of 18,061 patients from 65 studies. JACC Cardiovasc Interv. 2013; 6(2): 128-136, doi: 10.1016/j.jcin.2012.10.011, indexed in Pubmed: 23352817.

23. Meah MN, Ding WY, Joseph T, et al. Complex chronic total occlusion revascularization: a comparison of biradial versus femoral access. J Invasive Cardiol. 2021; 33(1): E52-E58, indexed in Pubmed: 33385987.

24. Tajti P, Xenogiannis I, Hall A, et al. Use of the dyevert system in chronic total occlusion percutaneous coronary intervention. J Invasive Cardiol. 2019; 31(9): 253-259, indexed in Pubmed: 31478890 .

25. Gupta A, Neupane S, Basir M, et al. Zero-iodinated contrast retrograde percutaneous coronary interventions of chronic total occlusions using gadolinium and imaging guidance: a case report of a patient with severe anaphylaxis to iodinated contrast. Eur Heart J Case Rep. 2020; 4(3): 1-7, doi: 10.1093/ehjcr/ytaa092, indexed in Pubmed: 32617458.

26. Chambers CE, Fetterly KA, Holzer R, et al. Radiation safety program for the cardiac catheterization laboratory. Catheter Cardiovasc Interv. 2011; 77(4): 546-556, doi: 10.1002/ccd.22867, indexed in Pubmed: 21254324.

27. Werner GS, Yaginuma K, Koch M, et al. Modulated radiation protocol achieves marked reduction of radiation exposure for chronic total coronary occlusion intervention. Catheter Cardiovasc Interv. 2021; 97(6): 1196-1206, doi: 10.1002/ccd.29132, indexed in Pubmed: 32667134.

28. Tsapaki V, Kottou S, Vano E, et al. Patient dose values in a dedicated Greek cardiac centre. Br J Radiol. 2003; 76(910): 726-730, doi: 10.1259/bjr/73325000, indexed in Pubmed: 14512333.

29. Werner GS, Yaginuma K, Koch M, et al. Reducing fluoroscopic and cineangiographic contribution to radiation exposure for chronic total coronary occlusion interventions. Cardiovasc Revasc Med. 2021 [Epub ahead of print], doi: 10.1016/j.carrev.2021.04.020, indexed in Pubmed: 33931375. 